\title{
Lower Critical Solution Temperature Phase Behavior of Natural Rubber/Polybutadiene Blend
}

\author{
Seiichi KaWAHara, ${ }^{\dagger}$ Yasuhiro Asada, Yoshinobu Isono, \\ Kiyoshige MuraOKA, ${ }^{*}$ and Yasuhisa MinAGAWA* \\ Department of Chemistry, Faculty of Engineering, Nagaoka University of Technology, \\ Nagaoka, Niigata 940-2188, Japan \\ * Material \& Process Laboratory, Research \& Development HQ, Sumitomo Rubber Industries, \\ Ltd., 1-1, 2-chome, Tsutsui-cho, Chuo-ku, Kobe 651-0071, Japan
}

(Received June 29, 2001; Accepted November 13, 2001)

\begin{abstract}
The lower critical solution temperature (LCST) phase behavior of the blend of natural rubber (NR) with polybutadiene (PB) having 32.3\% 1,2 unit was investigated by measuring $T_{\mathrm{g}}$ through DSC after annealing the blend. NR was separated with toluene into branched polymer and crosslinked one as a soluble fraction (NR-sol) and gel fraction (NR-gel), respectively, followed by mixing with PB. Coexistence composition of NR-sol/PB and NR-gel/PB blends was determined by a method proposed in this work using DSC. The LCST of the NR-sol/PB blend was $328 \mathrm{~K}$, being identical to the reported LCST of synthetic cis-1,4-polyisoprene/PB blend in our previous paper. The LCST of NR-gel/PB blend was quite similar to that of NR-sol/PB blend despite that NR-gel was crosslinked rubber $\left(v=1.5 \times 10^{-6}\right)$. Molecular weight was proved to produce no effect on the LCST phase behavior for high molecular weight polymer-polymer blend, i.e., $\mathrm{NR} / \mathrm{PB}$ blend.

KEY WORDS Natural Rubber / cis-1,4-polyisoprene / Polybutadiene / Blend / Miscibility / Lower Critical Solution Temperature (LCST) Phase Behavior /
\end{abstract}

Miscibility and phase behavior of a pair of polymers, composed of carbon and hydrogen, is one of the most important phenomena to study the attractive forces ${ }^{1-3}$ between dissimilar polymer chains, except for hydrogen bonding and charge transfer formations. To study these experimentally, a prudent selection of model polymers is important, because most high molecular weight hydrocarbons undergo crystallization or vitrification near ambient temperature, at which most experiments are carried out. We have investigated the miscibility and phase behavior for a blend of cis-1,4-polyisoprene (cis-1,4-PI) and polybutadiene (PB), which is regarded as liquid-like polymers, due to their low $T_{\mathrm{g}}$ and $T_{\mathrm{m}}{ }^{0}$, i.e., below room temperature.

In the previous study, ${ }^{4}$ we found that $\mathrm{PB}$ with low 1,2 unit content was immiscible with cis-1,4-PI, whereas the reverse is found for PB with higher 1,2 unit content. The phase boundary between the miscible and immiscible state was at $32.3 \% 1,2$ unit content, where the lower critical-solution-temperature (LCST) was observed to be $333 \mathrm{~K}$ for the blend. This phase transition was confirmed to take place reversibly and the mass transfer was proportional to the thermodynamic driving force,${ }^{5}$ $T-T_{\mathrm{s}}$, where $T$ is the annealing temperature and $T_{\mathrm{S}}$ is the spinodal temperature. Moreover, the extremely large negative excess volume on mixing ${ }^{6}$ and free vol- ume fraction apart from additive rule ${ }^{7}$ were observed as well as a conformational change on mixing estimated from spin-lattice relaxation time measured by pulsed NMR spectroscopy. ${ }^{8}$ These were proved positively by Roland, ${ }^{9}$ Hasegawa, ${ }^{10}$ Launger, ${ }^{11}$ Bahani, ${ }^{12}$ and Roovers, ${ }^{13}$ using various techniques respectively. However, the relationship between LCST and 1,2 unit content of PB, thus reported, was exclusively dependent upon the researchers. This was inferred to be due to the difference in molecular weight of the polymers, ${ }^{12}$ despite that cis-1,4-PI and PB used in the previous works were high molecular weight polymers.

To elucidate the effect of molecular weight on LCST of high molecular weight cis-1,4-PI/PB blend, we selected natural rubber (NR) and PB having 32.3\% 1,2 unit content. NR consists of $\omega$-terminal, two trans1,4-isoprene units, long sequence cis-1,4-isoprene units $\left(\bar{M}_{\mathrm{w}}\right.$ : about $\left.2 \times 10^{6}\right)$ and $\alpha$-terminal which is linked to phospholipid containing fatty acid ester group, aligned in that order, and it is rationally separated into soluble fraction (NR-sol) and insoluble fraction (NRgel) in toluene. ${ }^{14} \mathrm{NR}$-sol is branched polymer whose weight average molecular weight is about 2 million, ${ }^{14,15}$ whereas NR-gel is a crosslinked polymer having three dimensional network structures composed of physical crosslinks at the $\omega$-terminal due to protein and

${ }^{\dagger}$ To whom correspondence should be addressed (Tel: +81-258-47-9301, Fax: +81-258-47-9300, E-mail: kawahara@chem.nagaokaut. ac.jp). 
Table I. $\bar{M}_{\mathrm{w}}, \bar{M}_{\mathrm{w}} / \bar{M}_{\mathrm{n}}$ and crosslink density of NR-sol and NR-gel

\begin{tabular}{lccccc}
\hline Specimen & $\begin{array}{c}\bar{M}_{\mathrm{w}} / 10^{5} \\
(\text { LALLS })\end{array}$ & $\begin{array}{c}\bar{M}_{\mathrm{w}} / 10^{5} \\
(\mathrm{GPC})\end{array}$ & $\bar{M}_{\mathrm{w}} / \bar{M}_{\mathrm{n}}$ & $\begin{array}{c}v \text { from Mooney-Rivlin } \\
\text { constant } / 10^{-6} \mathrm{~mol} \mathrm{~g}^{-1}\end{array}$ & $\begin{array}{c}v \text { from equilibrium } \\
\text { swelling } / 10^{-6} \mathrm{~mol} \mathrm{~g}^{-1}\end{array}$ \\
\hline $\begin{array}{l}\text { NR-sol } \\
\text { NR-gel }\end{array}$ & 23.2 & 26.8 & 4.62 & 1.8 & 1.5 \\
PB & & 2.14 & 1.03 & & \\
\hline
\end{tabular}

chemical crosslinks at the $\alpha$-terminal linked to phospholipid. ${ }^{16}$ Since the physical crosslinks are held by aggregation of protein through hydrogen bonding formation, it may be cleaved by adding polar solvent, i.e., alcohol, resulting in dissolution of NR-gel into toluene. ${ }^{17}$ If PB is mixed with the dissolved NR-gel followed by removing polar solvent to form the three dimensional network structures, one may prepare a homogeneous crosslinked blend without segregation of the crosslinked polymers in the matrix.

In this work, we investigated the miscibility and phase behavior of ultra-high molecular weight cis-1,4$\mathrm{PI} / \mathrm{PB}$ and crosslinked cis-1,4-PI/PB blends, that is, NR-sol/PB and NR-gel/PB blends, respectively. The LCST phase behavior found for the blends was compared with the reported one. ${ }^{4}$

\section{EXPERIMENTAL}

\section{Sample Preparation}

Samples used in this study were commercial natural rubber (NR), that is, pale crepe, and polybutadiene prepared by anionic polymerization. Average molecular weights of the samples are shown in Table I. These were purified by reprecipitation using toluene and methanol. Natural rubber was cut into small pieces, whose dimension was about $1 \mathrm{~mm}^{3}$, and immersed into toluene for a week at room temperature under nitrogen atmosphere at a ratio of NR to toluene of 1:99 (w/v). The soluble fraction (NR-sol) was separated from insoluble fraction (NR-gel) by centrifugation at $14000 \mathrm{~g}$ for $30 \mathrm{~min}$. These were reprecipitated with methanol and dried under reduced pressure at room temperature for at least 1 week.

NR-sol and NR-gel were mixed with PB using toluene and toluene/methanol (9/1) solution, respectively. These were reprecipitated with methanol and dried under reduced pressure at room temperature until they reached constant weights.

\section{Measurements}

Measurements of molecular weight and molecular weight distribution of NR-sol and PB were made with a TOSOH GPC, consisting of a TOSOH CCPD pump, RI-8012 Differential Refractometer, UV-8011 UV detector and LS-8 low angle laser light scattering
(LALLS) detector. A column with the exclusion limit of about $4 \times 10^{7}$ was used in the analysis. The measurement was made at $303 \mathrm{~K}$ and the flow rate of the mobile phase, THF, was $0.5 \mathrm{~mL} \mathrm{~min}^{-1}$.

To estimate crosslink density, NR-gel was swollen in dried toluene for a week. The volume fraction of polymer, $\phi_{\mathrm{p}}$, in the swollen crosslinks was defined as follows:

$$
\phi_{\mathrm{p}}=1 /(1+Q)
$$

where

$$
Q=\frac{\text { [weight of solvent in network }]}{[\text { weight of network }]} \times \frac{\rho_{\mathrm{p}}}{\rho_{\mathrm{s}}}
$$

The modified Flory-Rehner equilibrium swelling equation $^{18,19}$ was used to determine the number of crosslinked chains per gram, $n$, as follows:

$$
n=\frac{-\left[\ln \left(1-\phi_{\mathrm{p}}\right)+\phi_{\mathrm{p}}+\chi \phi_{\mathrm{p}}{ }^{2}\right]}{\rho_{\mathrm{s}} V_{\mathrm{s}}\left(\phi_{\mathrm{p}}{ }^{1 / 3}-\phi_{\mathrm{p}} / 2\right)}
$$

Where $\chi$ is interaction parameter, i.e., 0.393 for NR in toluene, ${ }^{20} \rho_{\mathrm{p}}$ density of NR-sol, $0.915 \mathrm{~g} \mathrm{~cm}^{-3}, \rho_{\mathrm{s}}$ density of toluene, $0.865 \mathrm{~g} \mathrm{~cm}^{-3}$, and $V_{\mathrm{s}}$ molar volume of toluene, $92.14 \mathrm{~g} \mathrm{~mol}^{-1}$, respectively. Since $n$ is the effective number of moles of crosslinked chains per gram of polymer, the effective concentration of crosslinked chains, that is crosslink density, $v$, in moles per gram is estimated as $v=n / 2$.

The time-variation in strain of the film, prepared by casting the toluene-methanol solution onto glass plate, was measured at a constant stress, using traveling microscope.

${ }^{1} \mathrm{H}$ and ${ }^{13} \mathrm{C}$ NMR measurements were carried out at $323 \mathrm{~K}$ by a JEOL EX-400 NMR spectrometer at the pulse repetition time of $7 \mathrm{~s}$ and $5 \mathrm{~s}$, respectively. The pulse sequence of gated decoupling without nuclear Overhauser effect, NNE, was used for the quantitative analysis of diad sequence distribution and isomeric unit contents. The pulse repetition time for NNE measurements was set to be 10 times longer than the spin-lattice relaxation time. The polymer was dissolved into $\mathrm{CDCl}_{3}$ with small amount of TMS.

The miscibility and phase behavior of the blend were assessed by a measurement of glass transition temperature, $T_{\mathrm{g}},{ }^{21}$ using a Seiko Instruments DSC 220. The annealing-quenching procedure for NR/PB blend is schematically represented in Figure 1. The blend en- 


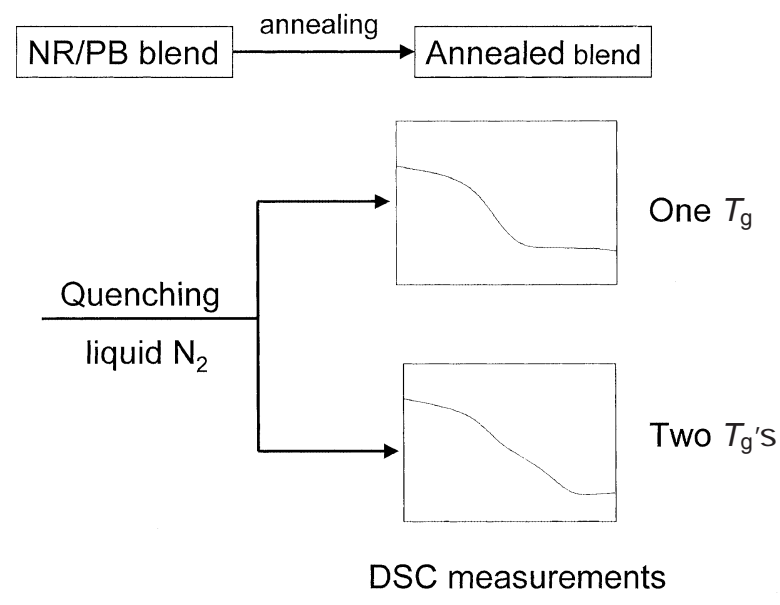

Figure 1. Thermal treatment procedure for NR/PB blend.

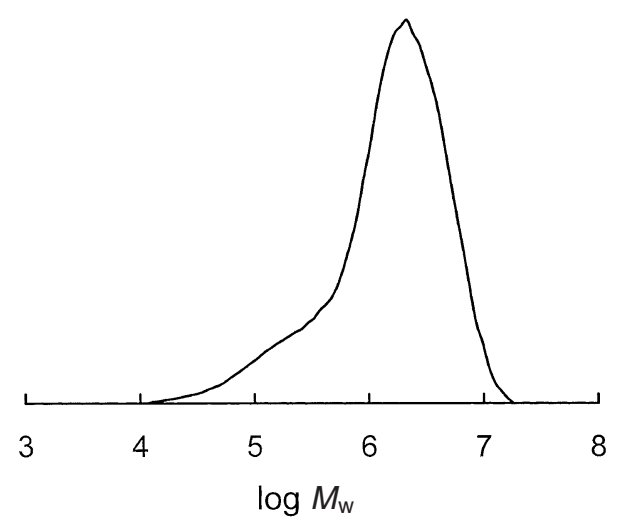

Figure 2. GPC curve of NR-sol.

capsulated in an aluminum pan was heated at an annealing temperature between $233 \mathrm{~K}$ and $373 \mathrm{~K}$ for at least $2 \mathrm{~h}$. The annealed blends were, then, quenched by immersing it directly into liquid nitrogen, in which the miscible or immiscible state, thus accomplished, was held due to vitrification of the blend. The miscible and immiscible states were assessed by $T_{\mathrm{g}}$ measurement at a heating rate of $10 \mathrm{~K} \mathrm{~min}^{-1}$ as one $T_{\mathrm{g}}$ and tow $T_{\mathrm{g}}{ }^{\prime} \mathrm{s}$ states, respectively.

\section{RESULTS AND DISCUSSION}

\section{Characterization of NR-sol, NR-gel, and PB}

Figure 2 shows a molecular weight distribution of NR-sol determined by gel permeation chromatography. The feature may be attributed to the bimodal distribution of molecular weight charasteristic of NR. ${ }^{14}$ The average molecular weight of the polymer was estimated using a calibration curve with standard polystyrene and it is tabulated in Table I. The weight average molecular weight, $\bar{M}_{\mathrm{wGPC}}$, and polydispersity, $\bar{M}_{\mathrm{w}} / \bar{M}_{\mathrm{n}}$, as well as the absolute weight average molecular weight, $\bar{M}_{\text {wLALLS }}$, thus determined, was quite similar to those reported in the previous study. ${ }^{22}$

NR-gel was characterized by measuring stress $v s$.

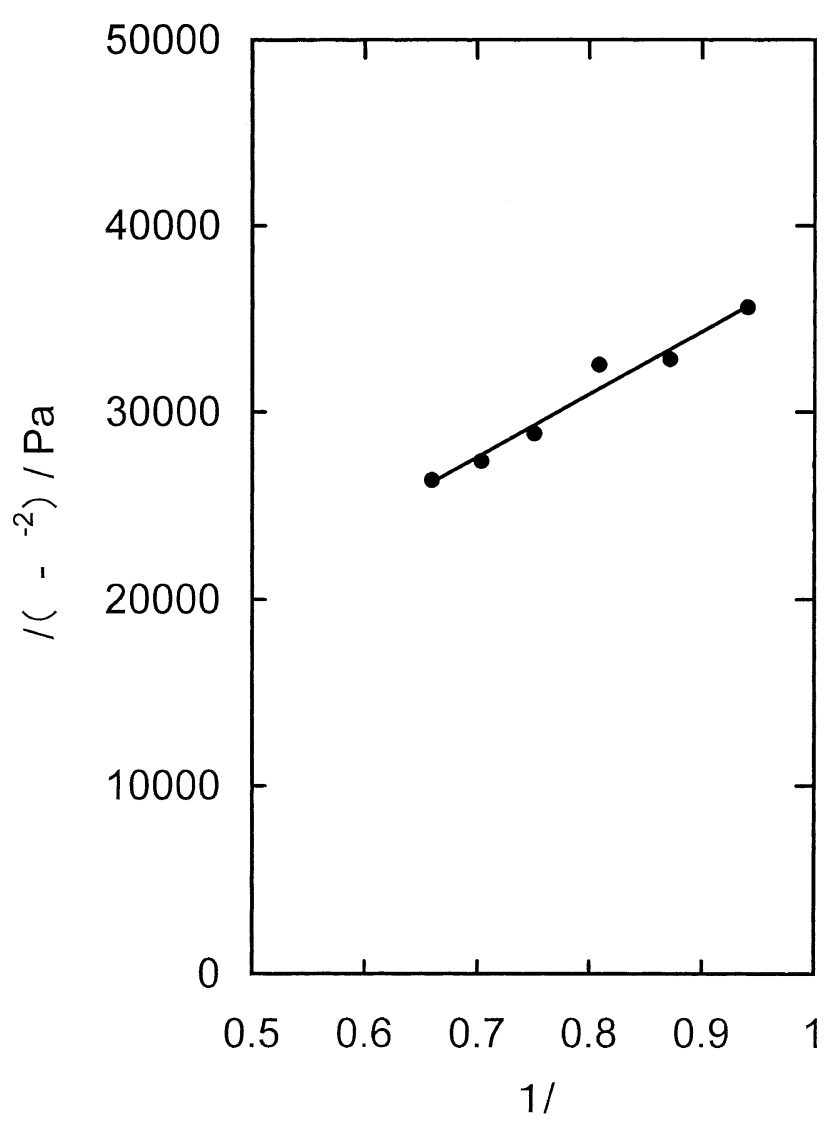

Figure 3. Mooney-Rivlin plot of NR-gel.

strain to prove the formation of three-dimensional network structure of the polymer. To estimate the crosslink density, $v$, Mooney-Rivlin expression ${ }^{23-25}$ was applied to the stress-strain relationship for NR-gel, as follows:

$$
\sigma /\left(\lambda-1 / \lambda^{2}\right)=2 C_{1}+2 C_{2} / \lambda
$$

where $\sigma$ is stress, $\lambda$ elongation, and $C_{1}$ and $C_{2}$ the Mooney-Rivlin constants, respectively. Figure 3 shows the Mooney-Rivlin plot for NR-gel. At the small strain, $\sigma /\left(\lambda-1 / \lambda^{2}\right)$ was proportional to $1 / \lambda$, due to the linear elastic behavior. As the strain increased, the non-linear behavior apart from the linear line was observed. Thus, the least-squares method was applied to the data points, being in the linear region, to estimate the MooneyRivlin constants. Table I shows the crosslink density, $v$, of NR-gel, estimated from the Mooney-Rivlin consta$\mathrm{nts}^{26}$ as well as equilibrium swelling measurement. The crosslink density estimated from the Mooney-Rivlin constants was quite similar to that estimated from the equilibrium swelling measurement. This is a supporting evidence that NR-gel is crosslinked polymer having three dimensional network structures composed of physical crosslinks at the $\omega$-terminal due to protein and chemical crosslinks at the $\alpha$-terminal linked to phospholipid, as reported in the previous paper. ${ }^{15}$

Isomeric unit contents of $\mathrm{PB}$ were determined by ${ }^{1} \mathrm{H}$ and ${ }^{13} \mathrm{C}$ NMR spectroscopy. Aliphatic carbon signals 
Table II. ${ }^{13} \mathrm{C}$ NMR chemical shifts of $\mathrm{PB}$

\begin{tabular}{|c|c|c|c|}
\hline \multirow{2}{*}{ Sequence } & \multirow{2}{*}{ Carbon } & \multicolumn{2}{|c|}{ Chemical shift/ppm } \\
\hline & & Sato et al. ${ }^{27}$ & Present work \\
\hline $\mathrm{C}-\mathrm{v}$ & 4 & $24.98-25.10$ & 24.92 \\
\hline $\mathrm{C}-1,4$ & 4 & $27.42-27.57$ & 27.46 \\
\hline $1,4-\mathrm{C}$ & 1 & & \\
\hline $\mathrm{T}-\mathrm{v}$ & 4 & 30.16 & 30.09 \\
\hline $\mathrm{v}-\mathrm{v}-\mathrm{C}(\mathrm{m})$ & 1 & $31.60-32.13$ & 32.18 \\
\hline $1,4-\mathrm{v}-\mathrm{C}$ & 1 & 32.72 & 32.71 \\
\hline $\mathrm{T}-1,4$ & 4 & & \\
\hline $1,4-\mathrm{T}$ & 1 & & \\
\hline $\mathrm{v}-\mathrm{v}-\mathrm{C}(\mathrm{r})$ & 1 & $33.35-33.53$ & 33.57 \\
\hline $1,4-V-1,4$ & 1 & $33.99-34.16$ & 34.08 \\
\hline $1,4-\mathrm{V}-\mathrm{v}(\mathrm{m})$ & 1 & 34.31 & 34.35 \\
\hline $1,4-\mathrm{V}-\mathrm{v}(\mathrm{r})$ & 1 & $35.63-36.00$ & 35.74 \\
\hline $\mathrm{v}-\mathrm{v}-\mathrm{T}(\mathrm{m})$ & 1 & $37.24-37.48$ & 37.59 \\
\hline $1,4-\mathrm{v}-\mathrm{T}$ & 1 & 38.18 & 38.14 \\
\hline$v-V-v$ & 2 & $38.57-39.13$ & 39.04 \\
\hline v-v-T(r) & 1 & $38.96-39.13$ & 39.51 \\
\hline $\mathrm{v}-\mathrm{V}$ & 1 & $39.43-41.72$ & 40.64 \\
\hline $1,4-\mathrm{V}-\mathrm{v}$ & 2 & $40.55-41.00$ & 41.08 \\
\hline $\mathrm{v}-\mathrm{V}-1,4$ & 2 & $41.13-41.73$ & 41.58 \\
\hline $1,4-V-1,4$ & 2 & $43.47-43.70$ & 43.60 \\
\hline
\end{tabular}

C, cis-1,4 unit; T, trans-1,4 unit; V, 1,2 unit; 1,4 cis- and trans-1,4 units m, meso; r, racemic.

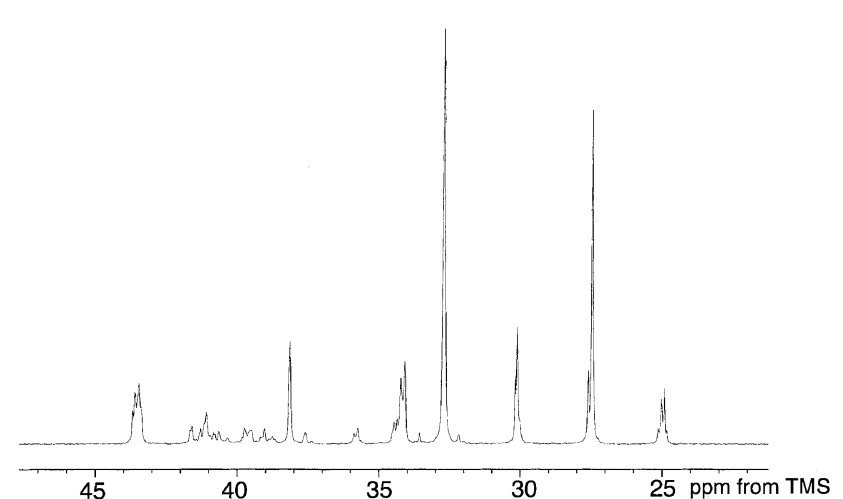

Figure 4. ${ }^{13} \mathrm{C}$ NMR spectrum of $\mathrm{PB}$.

of ${ }^{13} \mathrm{C}$ NMR spectrum for $\mathrm{PB}$ are shown in Figure 4. The signals were assigned to diad and triad sequences, according to the previous work. ${ }^{27}$ The chemical shifts of these signals were tabulated in Table II together with the assignment, thus far reported, where the carbon atoms in 1,4 and 1,2 units of PB are designated as follows:

$$
\begin{array}{rr}
-\mathrm{C}(1)-\mathrm{C}(2)=\mathrm{C}(3)-\mathrm{C}(4)-\quad-\mathrm{C}(2)-\mathrm{C}(1)- \\
\mathrm{I}(3)=\mathrm{C}(4) \\
\mathrm{C}(3)
\end{array}
$$

cis- 1,4

trans $-1,4$

As shown in Figure 4, all of the expected signals were shown in the spectrum. The diad sequence distribution and isomeric unit (microstructure) contents, estimated from the intensity ratios, are tabulated in Table III, together with the content of 1,2 unit determined
Table III. Diad sequence distribution and isomeric unit content of $\mathrm{PB}$

\begin{tabular}{lcc}
\hline Sequence & Obs/\% & Calcd $/ \%$ \\
\hline $\mathrm{C}-\mathrm{V}$ & 10.5 & 10.0 \\
$\mathrm{~T}-\mathrm{V}$ & 15.0 & 12.7 \\
$\mathrm{~V}-\mathrm{C}$ & 10.3 & 10.0 \\
$\mathrm{~V}-\mathrm{T}$ & 15.2 & 12.7 \\
$\mathrm{C}-1,4$ & 16.1 & 18.7 \\
$\mathrm{~T}-1,4$ & 19.6 & 23.7 \\
$\mathrm{~V}-\mathrm{C}$ & 13.2 & 12.2 \\
& & \\
cis- 1,4 & 28.7 & \\
trans $-1,4$ & 36.4 & \\
1,2 & 34.9 & \\
$1,2($ by & \\
\hline
\end{tabular}

C, cis-1,4 unit; T, trans-1,4 unit; V, 1,2 unit 1,4 cisand trans-1,4 units.

by ${ }^{1} \mathrm{H}$ NMR spectroscopy. The diad sequence distribution of trans-1,4, cis-1,4, and 1,2 units for PB, prepared by anionic polymerization using $n$-butyllithium, was random, as reported in our previous work, ${ }^{28,29}$ The content of 1,2 unit for PB determined by ${ }^{13} \mathrm{C}$ NMR measurement was similar to that determined by ${ }^{1} \mathrm{H}$ NMR measurement. Consequently, the PB used in the present study was confirmed to have the same 1,2 unit content as one used in our previous work. ${ }^{4}$

\section{LCST Phase Diagram}

It is widely recognized that an increase in molecular weight of polymers results in a reduction of a miscible region of polymer-polymer blends in $T-\phi$ phase 


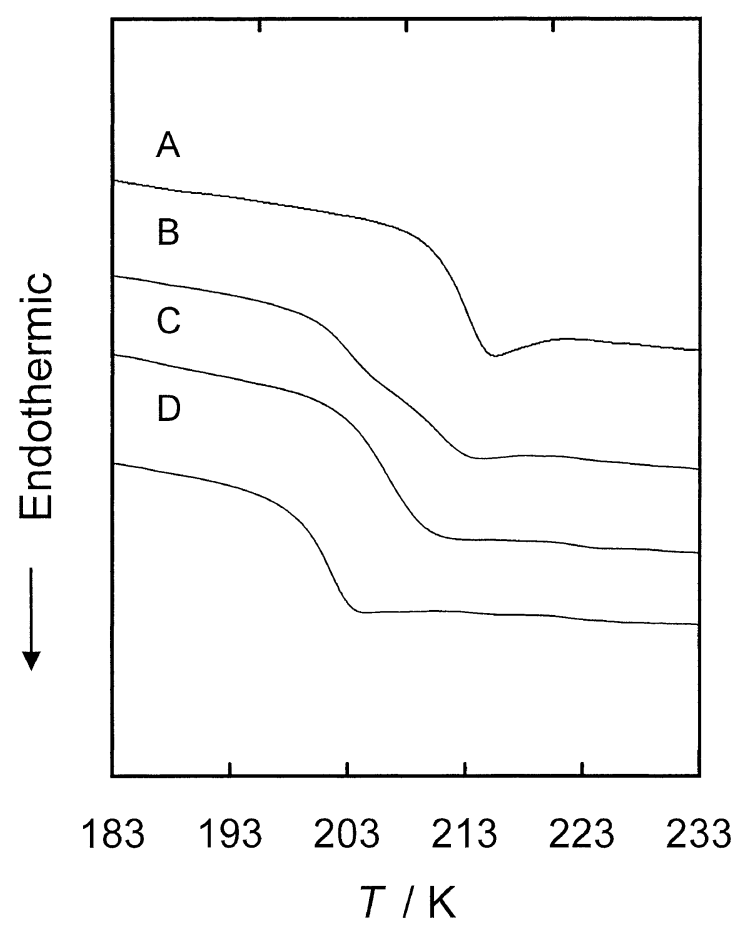

Figure 5. DSC thermogram of (A) NR-sol, (B) NR-sol/PB blend annealed at $358 \mathrm{~K}$, (C) NR-sol/PB blend at $298 \mathrm{~K}$ and (D) PB.

diagram. ${ }^{18}$ The effect of molecular weight on the miscibility is more prominent for a pair of lower molecular weight polymers compared to that of higher molecular weight polymers. This makes us consider that the LCST of PI/PB blend falls slightly down as the molecular weight of the polymer increases.

Figure 5 shows DSC thermograms of NR-sol, PB, and NR-sol/PB (50/50) blend, respectively. The blend at $298 \mathrm{~K}$, quenched by liquid nitrogen, showed one $T_{\mathrm{g}}$ between $T_{\mathrm{g}}{ }^{\prime} \mathrm{s}$ of NR-sol and PB. This demonstrates that NR-sol is miscible with PB, despite the ultra-high $\bar{M}_{\mathrm{w}}$. In contrast, Two $T_{\mathrm{g}}{ }^{\prime} \mathrm{s}$ were found for the blend annealed at $358 \mathrm{~K}$ for $2 \mathrm{~h}$, suggesting that a phase separation occurred. Consequently, the LCST phase behavior was found for NR-sol/PB blend, in which miscibleimmiscible phase transition took place repeatedly.

To draw LCST phase diagram, the NR-sol/PB blend was annealed at various temperatures between $233 \mathrm{~K}$ and $373 \mathrm{~K}$. Figure 6 shows a typical differential DSC thermogram of the blends, in which the differentiation was made to show $T_{\mathrm{g}}$ clearly because $T_{\mathrm{g}}$ 's of NR-sol and PB were very close to each other. At $298 \mathrm{~K}$, one $T_{\mathrm{g}}$ with a unimodal distribution was found, but it gradually changed to a bimodal distribution as the annealing temperature increased. The phase boundary between the miscible and immiscible state was at $328 \mathrm{~K}$ for the 50/50 blends. Furthermore, two peak-tops of the bimodal distribution were significantly dependent upon the annealing temperature. This may reflect coexis-

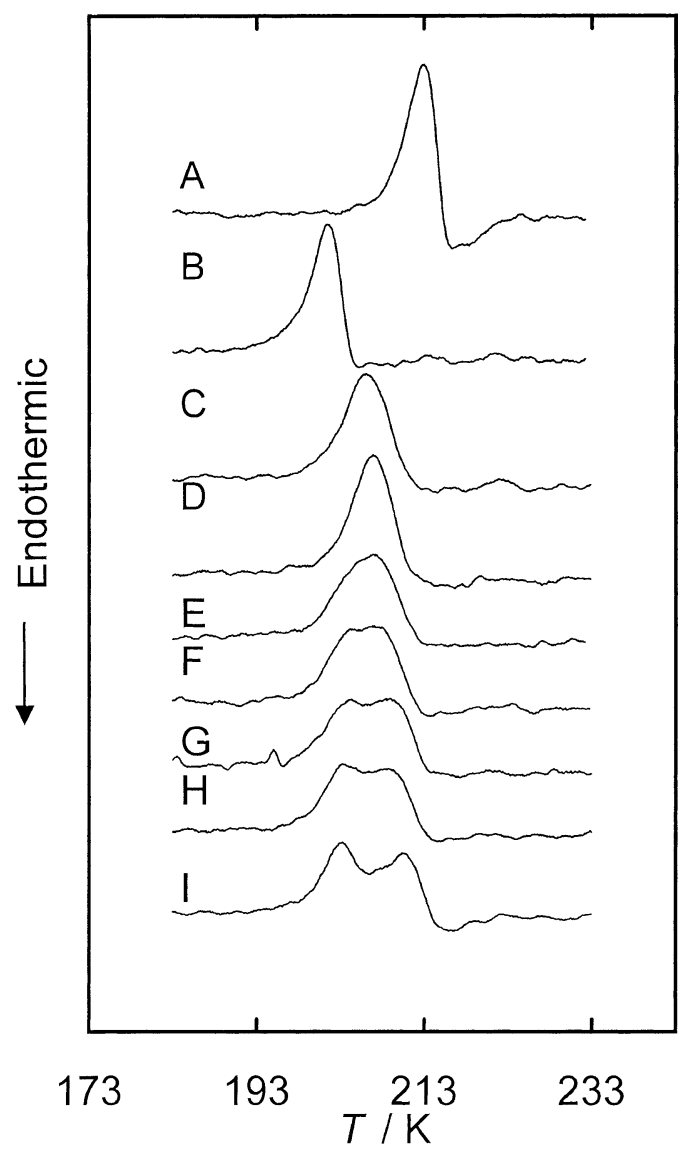

Figure 6. Differential DSC curve of (A) NR-sol, (B) PB, and NR-sol/PB (50/50) blend annealed at (C) 298, (D) 323, (E) 328, (F) $331,(\mathrm{G}) 333,(\mathrm{H}) 343$, and (I) $358 \mathrm{~K}$ for $2 \mathrm{~h}$.

tence compositions of two phases separated at the temperature.

Since $T_{\mathrm{g}}$ depends upon the composition of the blend, a $T_{\mathrm{g}}$-composition relationship was experimentally determined for NR-sol/PB blend. The differential DSC thermograms of the miscible blends, thus measured, are shown for the miscible blends in Figure 7. Only unimodal distribution was observed at the glass transition temperature region for the blends, and its peak-top was defined to be a $T_{\mathrm{g}}$. In Figure 8 is shown the $T_{\mathrm{g}} v s$. composition. The $T_{\mathrm{g}}$ was well-approximated as a function of composition, as follows:

$$
T_{\mathrm{g}}=2.6 W_{\mathrm{NR}-\mathrm{sol}}^{2}+7.4 W_{\mathrm{NR}-\mathrm{sol}}+203
$$

where $W_{\mathrm{NR} \text {-sol }}$ is weight fraction of NR-sol in the blend. This allows us to estimate a coexistence composition of each phase.

To determine $T_{\mathrm{g}}$ for the phase-separated blend shown in Figure 6 correctly, the overlapped two peaks of the bimodal distribution were subjected to peak-separation using a Gauss-Newton method, in which the distribution of onset of segmental motion was assumed to be Gaussian distribution. Figure 9 shows two peaks due to glass transition after the peak-separation. The temperature, at which the differential DSC is a maximum, was 


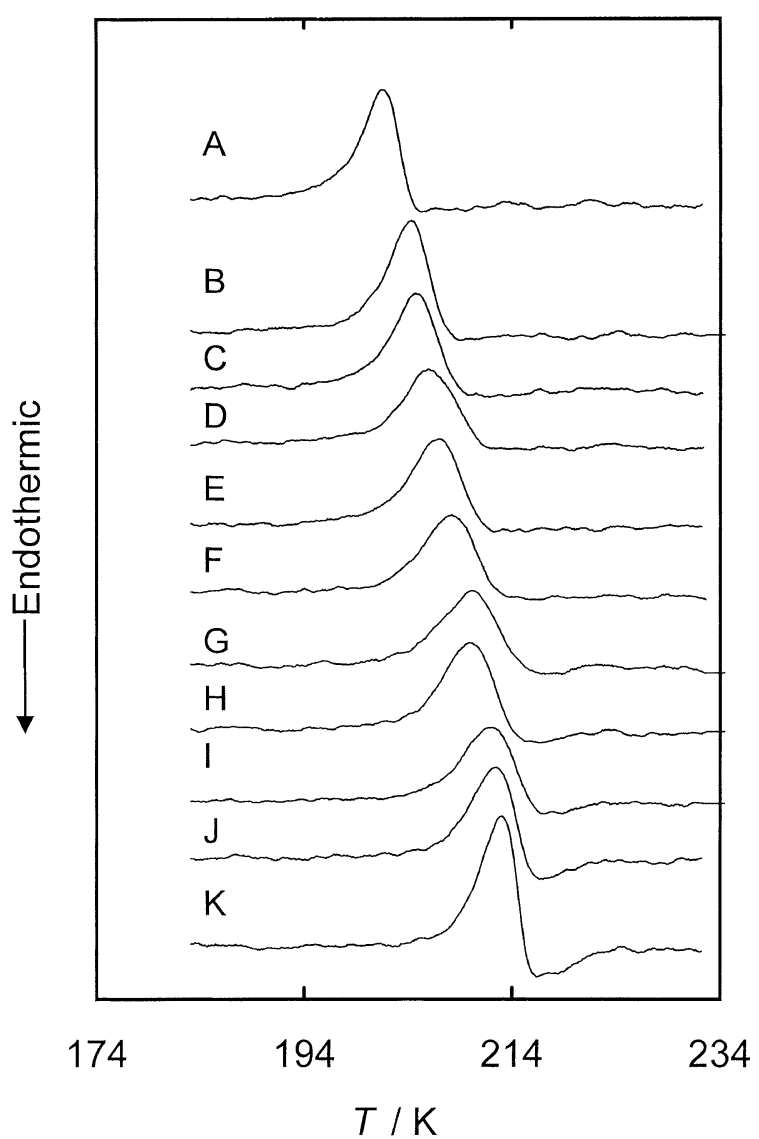

Figure 7. Differential DSC curve of (A) PB, (B) miscible NRsol/PB (90/10) blend, (C) (80/20), (D) (70/30), (E) (60/40), (F) (50/50), (G) (40/60), (H) (30/70), (I) (20/80), (J) (10/90), and NRsol.

defined to be $T_{\mathrm{g}}$. Thus, one may estimate the coexistence composition from the $T_{\mathrm{g}}$.

Figure 10 shows a typical change in the composition of NR-sol/PB (50/50) blend during phase separation at $373 \mathrm{~K}$. It is obvious that the blend underwent a phase separation immediately after annealing at $373 \mathrm{~K}$, as represented by a significant change in composition at the initial stage. After the composition reached a constant value, we determined the coexistence composition in the equilibrium state. The resulting coexistence curve is shown in Figure 11. The coexistence curve estimated using the (50/50) blend was consistent with those estimated using the (80/20), (70/30), and (60/40) blends. These were corresponding to the phase boundary between the miscible and immiscible state determined by $T_{\mathrm{g}}$ measurements, expressed as open circles and closed circles, respectively. This demonstrates that the coexistence curve, determined by the method proposed in this work, is binodal curve in the equilibrium state for the blend of ultra high molecular weight NR-sol with PB.

We also investigated the miscibility and phase behavior of NR-gel/PB blend. The differential DSC thermogram of NR-gel/PB (50/50) blend is shown in Figure 12 . The blend at $298 \mathrm{~K}$, quenched with liquid ni-

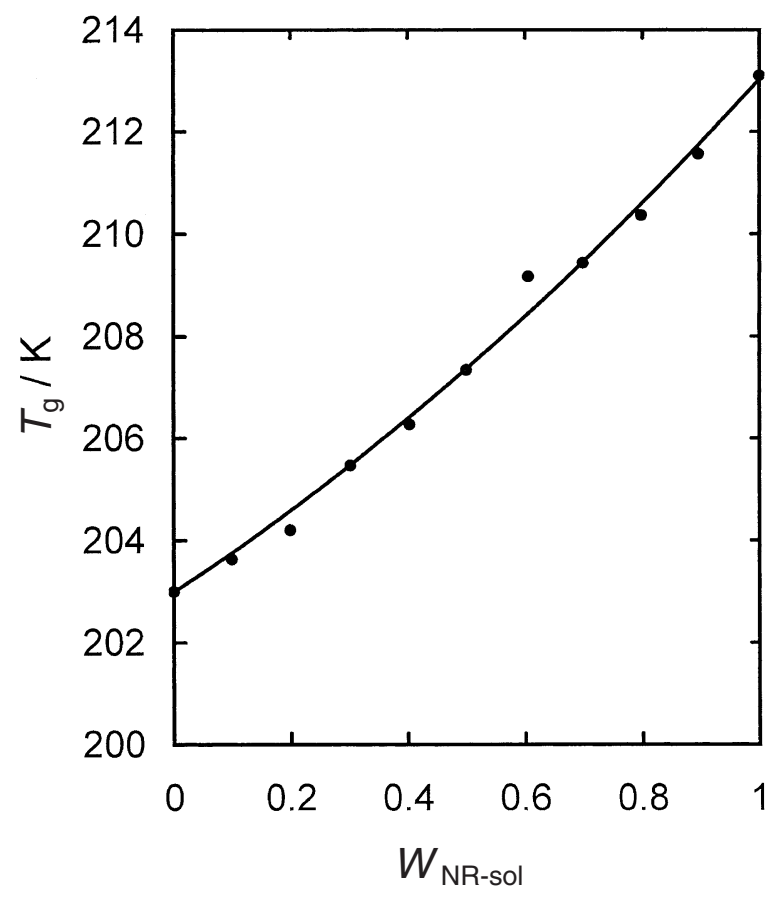

Figure 8. $T_{\mathrm{g}}$ of miscible NR-sol/PB blend.

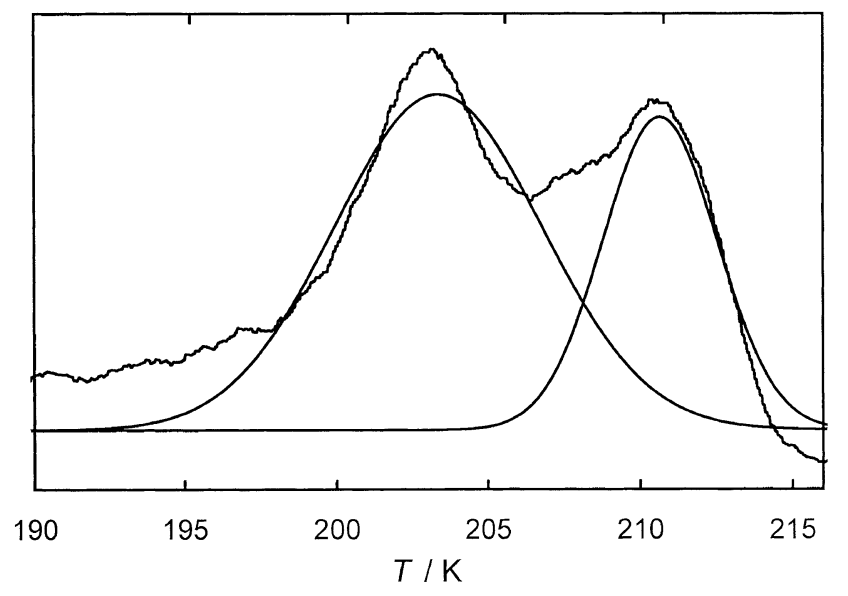

Figure 9. Peak-separation of bimodal distribution at $T_{\mathrm{g}}$ for NR-sol/PB blend annealed at $358 \mathrm{~K}$ for $2 \mathrm{~h}$.

trogen, showed one $T_{\mathrm{g}}$, suggesting that the blend was miscible in the order of about $10 \mathrm{~nm} \cdot{ }^{30}$ However, the blend underwent phase separation at $333 \mathrm{~K}, 343 \mathrm{~K}$, and $358 \mathrm{~K}$, as reflected by two $T_{\mathrm{g}}{ }^{\prime}$ s. Hence, the LCST phase behavior was also confirmed for the blend of NR-gel having three dimensional network structures with PB.

Figure 13 shows LCST phase diagram for the NRgel/PB blend, in which the coexistence compositions were estimated from $T_{\mathrm{g}}$ of NR-gel/PB (50/50) blend, using eq 5. The coexistence curve of NR-sol/PB blend is also shown in the Figure together with the reported miscible and immiscible regions for the blend of synthetic cis-1,4-PI with $\mathrm{PB},{ }^{4}$ which were determined by DSC to be one $T_{\mathrm{g}}$ and two $T_{\mathrm{g}}$ 's regions, respectively. The coexistence curve of NR-gel/PB blend appears at the same temperature-composition as that of NR- 


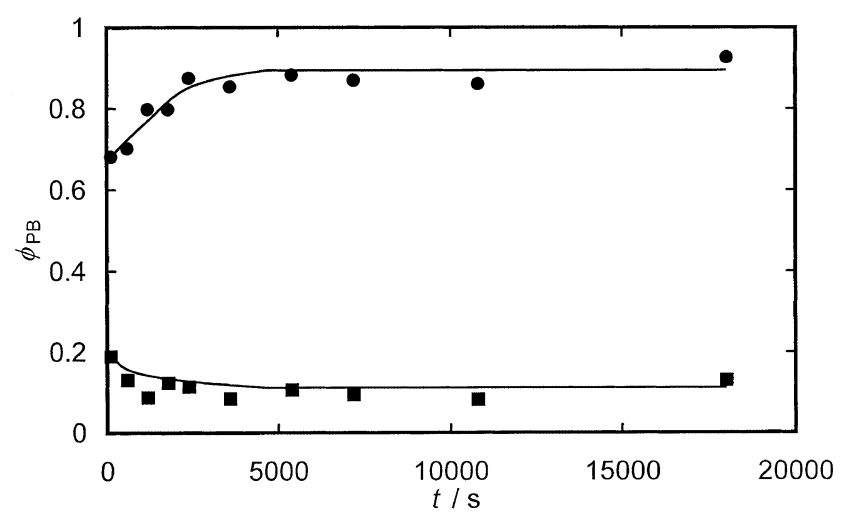

Figure 10. Time evolution of coexistence composition for NRsol/PB blend annealed at $373 \mathrm{~K}$ : (O) PB-rich phase and (ロ) NRsol-rich phase.

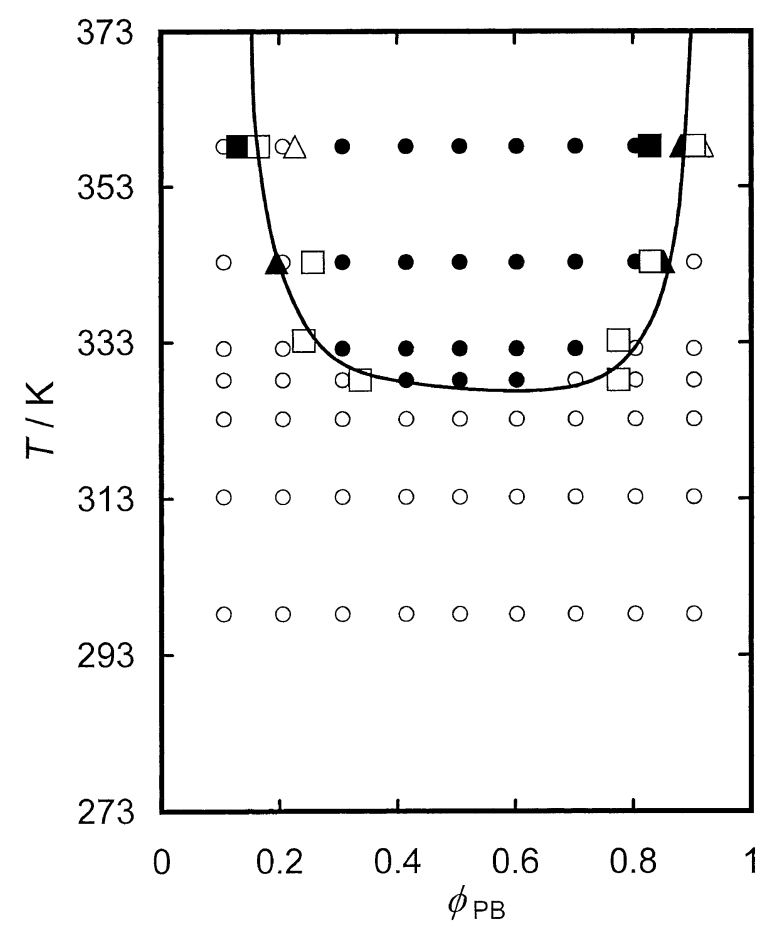

Figure 11. LCST phase diagram of NR-sol/PB blend, obtained by coexistence curve estimated using ( $\square)(50 / 50),(\mathbf{\square})(60 / 40),(\boldsymbol{\Lambda})$ (70/30), $(\triangle)(80 / 20)$ blends, and by $T_{\mathrm{g}}$ measurements: $(\mathbf{O})$, Two $T_{\mathrm{g}}{ }^{\mathrm{s}}$; $(\bigcirc)$, one $T_{\mathrm{g}}$.

sol/PB blend. Furthermore, these coexistence curves were corresponding to the reported phase boundary between the miscible and immiscible state for synthetic cis-1,4-PI/PB blend. ${ }^{4}$ Since we used PB having 32.3\% 1,2 unit content and $\bar{M}_{\mathrm{w}}$ of $2.14 \times 10^{5}$ to mix with NRsol and NR-gel in the present study, just same as those in the previous paper, ${ }^{4}$ the intermolecular attractive forces of these blends are expected to be the same as each other. The only difference is the molecular weight of cis-1,4-PI, i.e., $\bar{M}_{\mathrm{wGPC}}=2.68 \times 10^{6}$ for NR-sol, $7.30 \times 10^{5}$ for synthetic cis-1,4-PI, and $v=1.5 \times 10^{-6}$ for NR-gel. Therefore, it is concluded that the molecular weight of the polymer does not give a significant

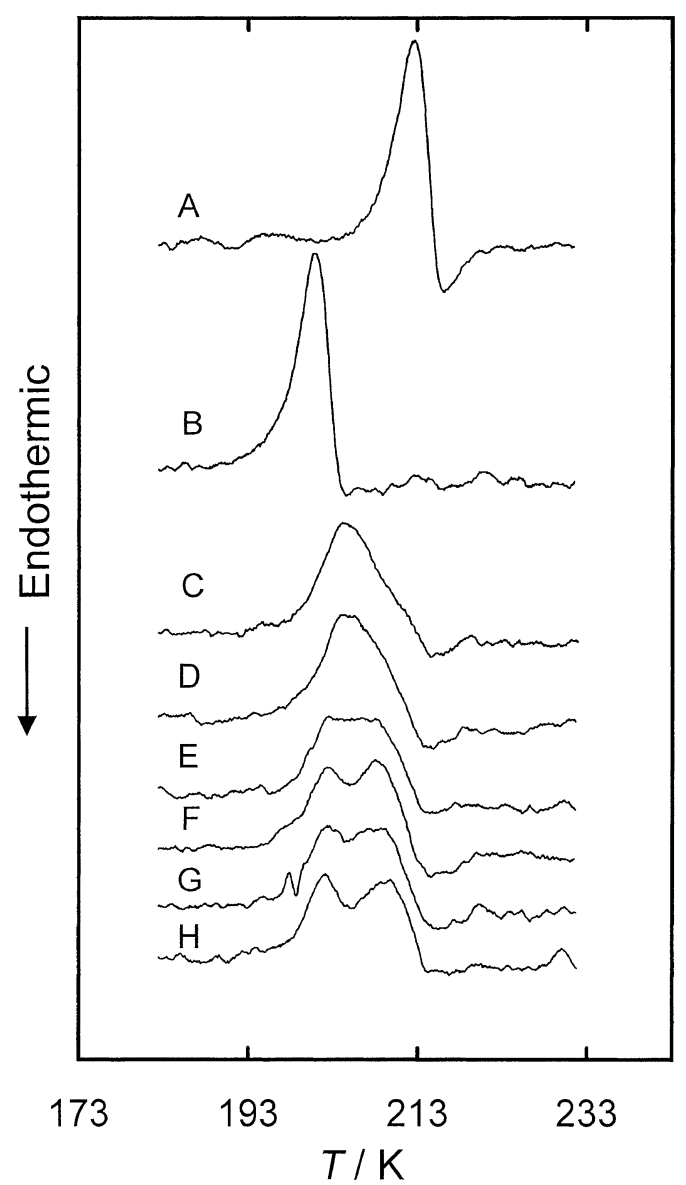

Figure 12. Differential DSC curve of (A) NR-gel, (B) PB and NR-gel/PB (50/50) blend annealed at (C) 298, (D) 323, (E) 328, (F) 333, (G) 343, and (H) $358 \mathrm{~K}$ for $2 \mathrm{~h}$.

influence on the LCST of NR-sol/PB, NR-gel/PB, and synthetic cis-1,4-PI/PB blends.

In the previous paper, ${ }^{12}$ Bahani, et al. reported the lower LCST for synthetic cis-1,4-PI/PB blend rather than that proposed in the present work. They inferred it to be due to the difference in the molecular weight, based upon the mean field approximation for a pair of polymers having the van der Waals attractive force. However, in the present study, we found that the effect of molecular weight was negligibly small on the LCST phase behavior at high molecular weight $>10^{5}$. Hence, the difference in LCST between Bahani's and us may be ascribed to a slight difference in 1,2 unit content of $\mathrm{PB}$, on which intermolecular interaction parameter should depends. The effect of 1,2 unit content of PB on the LCST phase behavior of NR/PB blend will be reported in the subsequent paper.

\section{CONCLUSION}

NR-sol and NR-gel were miscible with PB having $32.3 \% 1,2$ unit content at $298 \mathrm{~K}$, despite the ultra high molecular weight and three dimensional network struc- 


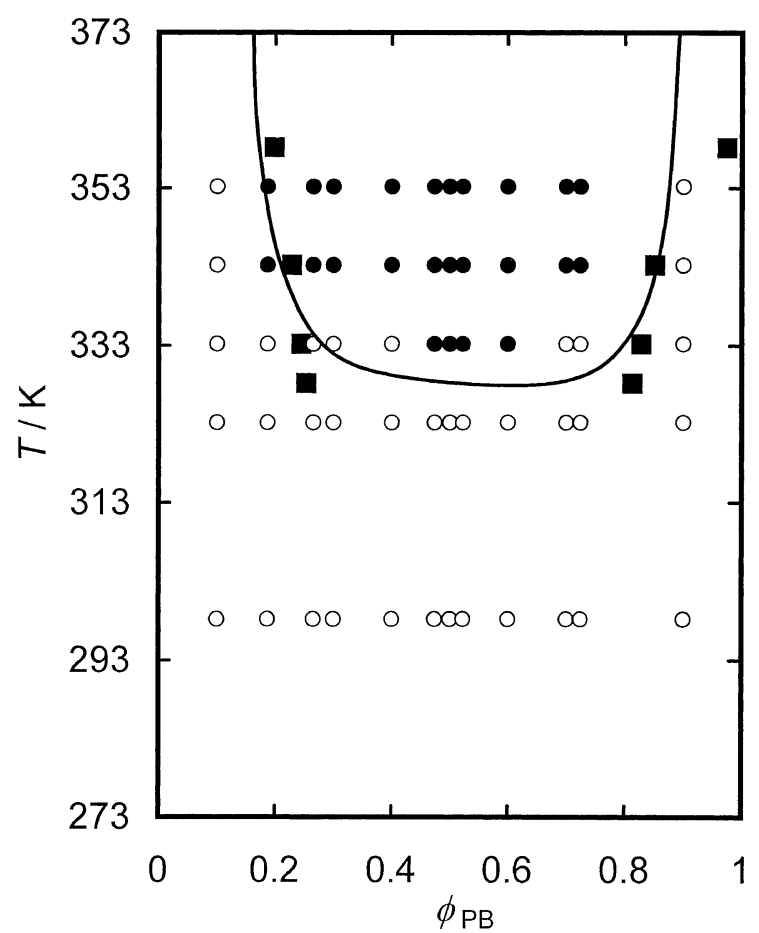

Figure 13. LCST phase diagram: (घ) for NR-gel/PB blend and solid line for NR-sol/PB blend. The reported LCST phase diagram for synthetic $c i s-1,4-\mathrm{PI} / \mathrm{PB}$ blend (ref 4) is also shown: (O), Two $T_{\mathrm{g}}{ }^{\prime} \mathrm{s} ;(\bigcirc)$, one $T_{\mathrm{g}}$.

ture that present in the two polymers, respectively. The LCST phase behavior was found for the NR-sol/PB and NR-gel/PB blends by the $T_{\mathrm{g}}$ measurements using DSC after quenching the annealed blends. The coexistence composition of NR-sol/PB and NR-gel/PB blends was determined by a method proposed in this work to draw the LCST phase diagram. The LCST of NR-sol/PB blend and NR-gel/PB blend was $328 \mathrm{~K}$, being identical to the reported LCST of synthetic cis-1,4-PI/PB blend. It is concluded that the difference in molecular weight plays no significant role in the LCST of NR-sol/PB, NR-ge1/PB and synthetic cis-1,4-PI/PB blends.

Acknowledgment. This work was supported in part by a Grant-in-Aid (12416) for the Development of Innovative Technology from the Ministry of Education, Culture, Sports, Science and Technology, Japan.

\section{REFERENCES}

1. S. Akiyama and S. Kawahara, 'Blends (Amorphous Rubbery Mixtures)' in 'The Polymeric Materials Encyclopedia', J. C. Salamone, Ed., CRC Press, Boca Raton, FL, 1996, p 699.

2. S. Kawahara and S. Akiyama, 'Non-ideal Mixing State of Rubber Blends' in "Advances in Polymer Blends and Alloys
Technology", Technomic Publishing Co., Inc., Lancaster, PA, 1994, vol. 5, chapt. 9.

3. For example:

S. Kawahara and S. Akiyama, Macromolecules, 26, 2428 (1993).

4. S. Kawahara, S. Akiyama, and A. Ueda, Polym. J., 21, 221 (1989).

5. S. Kawahara and S. Akiyama, Polym. J., 22, 361 (1990).

6. S. Kawahara and S. Akiyama, Polym. J., 23, 7 (1991).

7. S. Akiyama, S. Kawahara, I. Akiba, S. Iio, H.-H. Li, and Y. Ujihira, Polym. Bull., 45, 275 (2000).

8. S. Kawahara, K. Sato, and S. Akiyama, J. Polym. Sci., Polym. Phys. Ed., 32, 15 (1994).

9. C. M. Roland and C. A. Trask, Rubber Chem. Technol., 62, 456 (1989).

10. H. Hasegawa, S. Sakurai, M. Takenaka, and T. Hashimoto, Macromolecules, 24, 1813 (1991).

11. J. Launger, R. Lay, S. Maas, and W. Gronski, Macromolecules, 28, 7010 (1995).

12. M. Bahani, F. Laupretre, and L. Monnerie, J. Polym. Sci., Polym. Phys. Ed., 33, 167 (1995).

13. J. Roovers and P. M. Toporowski, Macromolecules, 25, 3454 (1992).

14. A.-H. Eng, S. Ejiri, S. Kawahara, and Y. Tanaka, J. Appl. Polym. Sci., Appl. Polym. Symp., 53, 5 (1994).

15. J. T. Sakdapipanich, T. Kowitteerawut, K. Suchiva, and Y. Tanaka, Rubber Chem. Technol., 72, 712 (1999).

16. Y. Tanaka, S. Kawahara, and J. Tangpakdee, Kautsch. Gummi Kunstst., 50, 6 (1997).

17. S. Kawahara, T. Kakubo, M. Suzuki, and Y. Tanaka, Rubber Chem. Technol., 72, 174 (1999).

18. P. J. Flory, "Principles of Polymer Chemistry", Cornell University Press, Ithaca, N.Y., 1953.

19. H. Adams and B. L. Johnson, Ind. Eng. Chem., 45, 1539 (1953).

20. C. J. Sheehan and A. L. Bisio, Rubber Chem. Technol., 39, 149 (1966).

21. R. P. Alexandrovich, F. E. Karasz, and W. J. MacKnight, Polymer, 18, 1022 (1977).

22. S. Kawahara, T. Kakubo, N. Nishiyama, Y. Tanaka, Y. Isono, and J. T. Sakdapipanich, J. Appl. Polym. Sci., 78, 1510 (2000).

23. M. Mooney, J. Appl. Phys., 11, 582 (1940).

24. M. Mooney, J. Appl. Phys., 19, 434 (1948).

25. R. S. Rivlin, Philos. Trans. R. Soc. London. Ser. A, 240, 459 (1948).

26. L. Mullins, J. Appl. Polym. Sci., 2, 257 (1959).

27. H. Sato, K. Takebayashi, and Y. Tanaka, Macromolecules, 20, 2418 (1987).

28. Y. Tanaka, S. Kawahara, T. Ikeda, and H. Tamai, Macromolecules, 26, 5253 (1993).

29. K. Kakuta, H. Tamai, P.-F. Howng, S. Kawahara, and Y. Tanaka, Macromolecules, 32, 5994 (1999).

30. K. C. Frish, D. Klempner, and H. L. Frish, Polym. Eng. Sci., 22, 1143 (1982). 